\title{
Present Medical Research: Is it Really Original Research Anymore?
}

\author{
Udaya M Kabadi* \\ Adjunct Professor of Medicine, University of Iowa and Des Moines University, USA
}

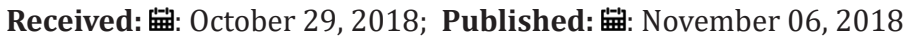

*Corresponding author: Udaya M Kabadi, Adjunct Professor of Medicine, University of Iowa and Des Moines University, 17185 Berkshire Parkway Clive, Iowa 50325, USA

\section{Introduction}

I have been a faculty member at several medical institutions in USA for almost 44 years. I am thoroughly disappointed at the quality of present medical research in comparison to research conducted until the turn of the century. I propose the following reasons for the decline in the quality.

\section{Epidemiological studies}

Retrospective studies were then shunned by most prestigious and established journals. Presently, a large majority of the articles published in these same journals happen to be conducted by a retrospective design. Unfortunately, almost all these studies are epidemiological in nature demonstrating association between one parameter and another using a statistical analysis establishing 'Relative Risk or Hazard Ratio'. Moreover, most of these studies conduct 'multivariate' analyses and often artificially eliminate multiple variables to satisfy the associations between pre-decided parameters [1]. Finally, RR is almost always statistically significant even with a miniscule ratio (1.1) because of data retrieval in very large populations obtained from registries as well national health and insurance websites via internet and electronic medical records. It must be mentioned that statistical significance often does not translate into clinical significance.

Most frequent design used in these retrospective analyses is to divide a population into tertile or quartile groups based on levels of a metabolite and determination of RR between the metabolite with predecided outcomes. Almost none of these studies document significant correlations between the metabolite and outcomes or attempt to establish pathophysiologic or cause and effect' relationships. The prime example is 'Vitamin D deficiency' and almost all ills in mankind [2]. In fact, vitamin D supplementation has apparently evolved into a big industry despite total lack of evidence showing remission or even improvement in almost all these disorders following vitamin D supplementation even with megadoses [2]. Association between oral antihyperglycemic agents and cardiovascular morbidity as well as mortality in subjects with type 2 Diabetes without consideration of variability of other important metabolites such as HbA1c, lipid panel and other cardiovascular risk markers using retrospective registry analysis is another prominent example [3-5]. List of similar examples is too large and is beyond the scope of this essay. Unfortunately, this design is being implemented to document increased incidence of a known adverse effects of the drug in comparison to placebo, e.g. greater relative risk of hyponatremia and hypokalemia with a use of diuretic in comparison to other non-diuretic comparators [6]. Sooner than later, a study may appear in the literature showing increased prevalence of hypoglycemia in subjects with diabetes using insulin in comparison to normal subjects administered a placebo.

\section{Meta-analysis}

During the last 20 years of the 20th century, medical research funding in USA by private foundations, pharmaceutical companies, major institutions as well as the governmental agencies declined precipitously. Moreover, studies with enrollment of large populations, e.g. over a thousand were not funded by governmental agencies such as National Institute of Health probably because of earlier government sponsored clinical trials such as University Group Diabetes Program creating major controversies [7-9]. Moreover, many long-term population studies such as very wellrespected Framingham cardiovascular outcome trial primarily involved Caucasian families [10,11]. Unfortunately, the results of this study are still being applied to subjects belonging to other ethnic groups, e.g. African Americans, Asians, South Americans 
etc. As a result, the lack of adequate funding for studying large populations gave way to a new study design of 'meta-analysis' requiring very little or no funding.

Thus, meta-analysis has become 'poor researcher's design to examine data in a large population by involving multiple studies with small populations of subjects. The methodology has become extremely accessible since the advent of internet because of easy retrieval of literature on websites such as 'pub med, medline, google search' etc. Easy access to interested colleagues and a statistician in the department of a major medical institution is primary requisite. Thus, meta analyses are apparently a 'second hand research' a poor substitute for a large population study. Unfortunately, even the pharmaceutical companies are taking advantage of this design by reporting individual clinical trial with enrollment of relatively small populations and reporting a meta-analysis involving the same clinical trials arriving at almost identical conclusions at a later date. For example, many of the individual clinical trials using GIP1 Receptor agonists failed to report increased prevalence of acute pancreatitis and Meta-analysis arrived at the same conclusion obviously because it included the same individual clinical trials [12]. Similar meta analyses have been reported using clinical trials with other drugs as well $[13,14]$. A major drawback of the meta-analysis is the biases of the researchers regarding inclusion and exclusion criteria for the small studies depending on the similarities of the subjects, the methodologies as well as predetermined outcomes. Hence, the conclusions are are frequently questionable and must be critically examined and interpreted. These aforementioned limitations of meta-analysis design are recently very well described [15-17].

\section{Multinational clinical trials}

Many major pharmaceuticals have recently embarked upon worldwide multinational clinical trials examining the efficacy as well as safety of their drugs in treatment of chronic disorders, e.g. Diabetes, Hypertension, dyslipidemia on cardiovascular outcomes etc [18]. Apparently, there are several major flaws in the designs of these trials [19-21]. Reporting of the data in the total population irrespective of diversity of ethnicity of the subjects, differences in prominent pathophysiology of disorders in populations with these diversities is a major drawback. Decline in insulin secretion in lean subjects especially of southeast Asian origin in contrast to the rise in insulin resistance in obese Americans with type 2 Diabetes [22$24]$ or increase in cardiac output and circulating blood volume as a major causative contributor in African Americans in contrast to rising peripheral vascular resistance as a main pathophysiologic factor of hypertension in subjects with other ethnicities are distinctly of importance in the outcomes.

Moreover, variability in prevalence of disorders in populations of different diverse backgrounds is also likely to alter predetermined outcomes. Alternatively, lack of uniformity of methodology because variability of use of medications and goals of therapy for these disorders based on criteria developed by medical organizations of individual nation may be another fraudulent factor. More- over, the uniformity in the methodology is even further compromised by leaving the choice of the strategy of management of the disorder to the discretion of the individual investigator. Finally, sponsorships and funding of these trials by pharmaceutical companies also raise questions regarding the integrity and reliability of the conclusions since the major incentive for the sponsors is to obtain approval and marketing of drugs in order to generate profits and improve their financial future. Therefore, it is apparent that the data in these trials must be confirmed by additional repetitive results conducted by institutions, agencies or investigators independent of and not connected in any way with pharmaceuticals. Alternatively, the initial trials must be conducted by the same independent entities in order to establish the integrity, purity and reliability of. conclusions. Recently, the integrity and reliability of even short-term clinical trials has also been questioned because of the participation by a few same investigators (20\%) in development of the design and performance of most (80\%) of the trials [25-27]. It is apparent that these few investigators have created 'clinical trial mills' by developing a data base of subjects who hop from one trial to another thus compromising the integrity and reliability. In conclusion, recent medical research appears to utilize inferior designs in terms of methodologies and may also be devoid of highest integrity, accuracy and reliability.

\section{References}

1. Tetrault JM, Sauler M, Wells CK, Concato J (2008) Reporting of multivariable methods in the medical literature. J Investig Med 56(7): 954-957.

2. Khan M, Kabadi U (2011) Vitamin D in Health and Disease, Primary care Reports (17).

3. Simpson SH, Majumdar SR, Tsuyuki RT, Eurich DT, Johnson JA (2006) Dose-Response Relation between Sulfonylurea Drugs and Mortality in Type 2 Diabetes Mellitus: A Population-Based Cohort Study. Canadian Medical Association Journal 174(2): 169-174.

4. Tzoulaki I, Molokhia M, Curcin V, Little MP, Millett CJ, et al. (2009) Risk of Cardiovascular Disease and All-Cause Mortality among Patients with Type 2 Diabetes Prescribed Oral Antidiabetes Drugs: Retrospective Cohort Study Using UK General Practice Research Database. BMJ 339, b4731.

5. Morgan CL, Mukherjee J, Jenkins Jones S, Holden SE, Currie CJ (2014) Association between First-Line Monotherapy with Sulphonyl urea versus Metformin and Risk of All-Cause Mortality and Cardiovascular Events: A Retrospective, Observational Study. Diabetes Obesity and Metabolism 16(10): 957-962.

6. Barber J, McKeever TM, McDowell SE, Clayton JA, Ferner RE, et al. (2015) A systematic review and meta-analysis of thiazide-induced hyponatraemia: time to reconsider electrolyte monitoring regimens after thiazide initiation? Br J Clin Pharmacol 79(4): 566-577.

7. Goldner MG, Knatterud GL, Prout TE (1971) Prout TE Effects of hypoglycemic agents on vascular complications in patients with adultonset diabetes. 3. Clinical implications of UGDP results. JAMA 218(9): 1400-1410.

8. Seltzer HS, Seltzer (1972) Avoiding the pitfalls of long-term therapeutic trials: lessons learned from the UGDP study. J Clin Pharmacol New Drugs 12(10): 393-398.

9. Prout TE, Knatterud GL, Meinert CL, Klimt CR (1972) The UGDP controversy. Clinical trials versus clinical impressions. Diabetes 21(10): 1035-1040. 
10. Chen G, Levy D (2016) Contributions of the Framingham Heart Study to the Epidemiology of Coronary Heart Disease. JAMA Cardiol 1(7): 825830.

11. Mahmood SS, Levy D, Vasan RS, Wang TJ (2014) The Framingham Heart Study and the epidemiology of cardiovascular disease: a historical perspective. Lancet 383(9921): 999-1008.

12. Karagiannis T, Liakos A, Bekiari E, Athanasiadou E, Paschos P, et al (2015) Efficacy and safety of once-weekly glucagon-like peptide 1 receptor agonists for the management of type 2 diabetes: a systematic review and meta-analysis of randomized controlled trials. Diabetes Obes Metab 17(11): 1065-1074.

13. Monami M, Nardini C, Mannucci E (2014) Efficacy and safety of sodium glucose co-transport-2 inhibitors in type 2 diabetes: a meta-analysis of randomized clinical trials. Diabetes Obes Metab 16(5): 457-466.

14. Ritzel R, Roussel R, Bolli GB, Vinet L, Brulle Wohlhueter C, et al. (2015) Patient-level meta-analysis of the EDITION 1, 2 and 3 studies: glycaemic control and hypoglycaemia with new insulin glargine $300 \mathrm{U} / \mathrm{ml}$ versus glargine $100 \mathrm{U} / \mathrm{ml}$ in people with type 2 diabetes. Diabetes Obes Metab 17(9): 859-867.

15. Cornell JE, Liao JM, Stack CB, Mulrow C (2017) Annals Understanding Clinical Research: Evaluating the Meaning of a Summary Estimate in a Meta-analysis. Ann Intern Med 167(4): 275-277.

16. Gurevitch J, Koricheva J, Nakagawa S, Stewart G (2018) Meta-analysis and the science of research synthesis. Nature 555(7695): 175-182.

17. Nikolakopoulou A, Mavridis D, Furukawa TA, Cipriani A, Tricco AC, et al. (2018) Living network meta-analysis compared with pairwise metaanalysis in comparative effectiveness research: empirical study. BMJ 360: k585.

18. Kabadi UM (2018) Confusion over guidelines about desirable goals in subjects with diabetes, hypertension and dyslipidemia. Global Journal of Endocrinological Metabolism 1(5): 1-2.

\section{ISSN: 2574-1241}

DOI: $10.26717 / B J S T R .2018 .10 .002007$

Udaya M Kabadi. Biomed J Sci \& Tech Res

CC (i) This work is licensed under Creative

Commons Attribution 4.0 License

Submission Link: https://biomedres.us/submit-manuscript.php
19. Zinman B, Wanner C, Lachin JM, David Fitchett, Erich Bluhmki, et al. (2015) Empagliflozin, Cardiovascular Outcomes, and Mortality in Type 2 Diabetes. New England Journal of Medicine 373: 2117-2128.

20. Marso SP, Daniels GH, Brown-Frandsen K, Kristensen P, Mann JF, et al. (2016) LEADER Steering Committee; LEADER Trial Investigators. N Engl J Med 375(4): 311-322.

21. Kabadi UM (2017) cardiovascular outcome trials in type 2 diabetes: reliable or biased! World Journal of Pharmaceutical and Medical Research 3(11): 33-35.

22. Kabadi UM (2013) Comparative Efficacy between Glimepiride and Metformin in Preventing Progression of Prediabetes to Type 2 Diabetes. Journal of Diabetes Mellitus 3(3): 129-133.

23. Esmail R, Kabadi U (2016) Improvement in Cardiovascular Risk Markers with Glimepiride in Non Obese Subjects with Pre-Diabetes: Similar to Obese Cohort Treated with Metformin. British Journal of Medicine \& Medical Research 18(8): 1-6.

24. Kabadi U (2017) Major Pathophysiology in Prediabetes and Type 2 Diabetes: Decreased Insulin in Lean and Insulin Resistance in Obese. J Endocr Soc 1(6): 742-750.

25. Holleman F, Uijldert M, Donswijk LF, Gale EA (2015) Productivity of Authors in the Field of Diabetes: Bibliographic Analysis of Trial Publications. BMJ 351: h2638.

26. Wager E (2015) Are Prolific Authors Too Much of a Good Thing? BMJ 351: h2782.

27. Kabadi UM (2016) New Oral Diabetes Drugs are more effective than Older Agents: Real or a Fraud? Journal of Diabetes, Metabolic Disorders \& Control 3(3): 1-4.

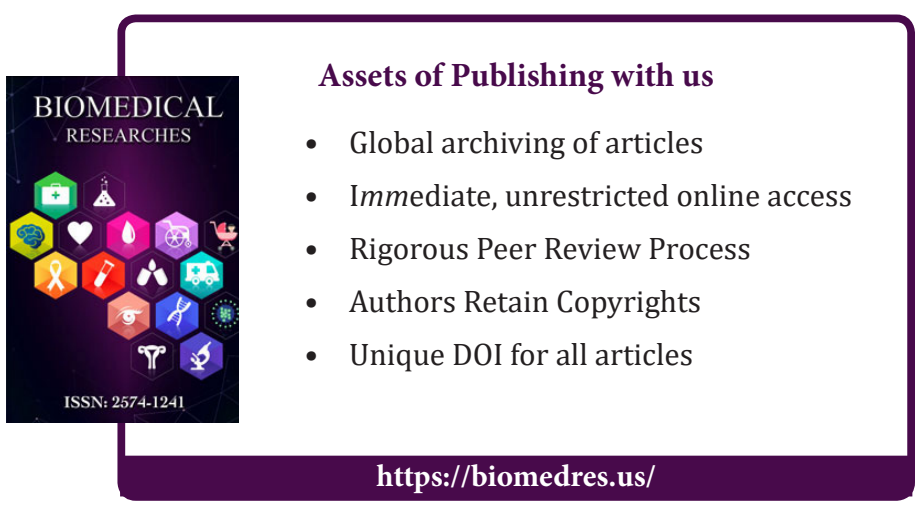

